\title{
Personality Traits among Entrepreneurial and Professional
}

\section{CEOs in SMEs}

\author{
H. MUSHTAQ AHMAD (Assistant Professor) \\ Department of Management Sciences, Bahria University Islamabad \\ Shangrila Road, E-8, Islamabad, Pakistan \\ Tel: 92-0333-5167-865 E-mail: mushtaq@bahria.edu.pk
}

\begin{abstract}
This is a descriptive, quantitative, and hypotheses testing study conducted on entrepreneurial and professional CEOs. This study has a particular interest in small medium enterprises (SMEs) because it constitutes the core of our economy and is a major factor of social composition. The purpose of present study is to investigate and explore differences on the motivational profile of Pakistani entrepreneurial and professional CEOs based on motivational profiles. This paper investigates the area that remained ignored in Pakistan and examines how entrepreneurial are different from professional CEOs and identifies differences on the basis of motivational profile between entrepreneurial and professional CEOs.

The finding of the study reveals that there is a significant difference in motivational profiles between entrepreneurial CEOs and Professional CEO. Contrary to that professional CEOs scored lower on these but higher on type-A personality.
\end{abstract}

Keywords: Personality traits, Entrepreneurship, Entrepreneurs, Entrepreneurial CEOs, Professional CEOs, Small Medium Enterprises

\section{Introduction}

In this dynamic business world entrepreneurship has inferred special significance, as it is a key driver to economic development. The objectives of industrial development, regional growth, and employment generation depend upon entrepreneurship. Entrepreneurship and entrepreneurs have altered the pathways of economies, and markets. They have developed new products and services. They give way to innovation and creativity which is a vital tool for economic development and prosperity. Since the economists have capitalized the imperative role of entrepreneurs in economic and social growth, the entrepreneur was considered the mechanism for transforming and improving the economy. Insights into the entrepreneurs role under an economic perspective were described by various scholars such as uncertainty bearing role of the entrepreneur (Cantillon, 1993), coordination function (Jean Baptists, 1845), innovation function (Marshall, 1961; Knight, 1921; Schumpeter, 1934; and kirzner, 1981, Bosam et al, 2000, Sexton and Bowman, 1985).

Entrepreneurship is defined as a process of creating something different with value by developing the necessary time and effort, assuming the various factors such as financial, physical, and social risks, for rewards of monetary and personal satisfaction (Hisrich and Brush, 1985). Because of its importance towards GDP and employment creation by entrepreneurship, both governments and academics are aiming at encouraging entrepreneurship. Entrepreneurship symbolizes innovation and a dynamic economy (Orhan and Scott, 2001). Several theories and observations have been expressed concerning the motivation of the entrepreneurs and several characteristics have been said to distinguish entrepreneurial CEOs from professional CEOs or top managers. Previous research has not been succeeded to isolate psychological dimensions which differentiate successful entrepreneurs from less successful or unsuccessful ones (Sexton and Bowman, 1984). Personality and entrepreneurship studies have now been undertaken which has found evidence that entrepreneur traits appear to differ secularly from those of managers with respect to some elements of basic personality (Thompson, 2009). Past study describes that personality traits is one of the most common psychological theories used to explain and predict human behavior, including entrepreneurship (Kautonen et al, 2009). A question arises here, are these characteristics identical to those which discriminate entrepreneurs from managers? It is nice to talk about that entrepreneur is a person who has founded his or her own organization. To answer the above raised questions, the present study will explore the relationship on the basis of psychological attributes of entrepreneurial and professional CEOs or top managers.

The present study is based on a group of Pakistani entrepreneurial CEOs and professional CEOs or top managers. This study has a particular interest in small medium enterprises (SMEs) because it constitutes the core of our 
economy and is a major factor of social composition. SMEs in Pakistan create job opportunities and promote economic growth, both regional and national level. SMEs employing up to almost 99 persons, constitutes $90 \%$ of all private enterprises in the industrial sector and employ some $78 \%$ of all non agriculture labor force. SMEs contribute over $30 \%$ to GDP. Based upon the literature the study set to examine how the five important motivational motives such as the need for achievement, locus of control, risk taking propensity, ambiguity tolerance, and type-A personality distinguish personal traits and leadership style and of entrepreneurial and professional CEOs.

This paper investigates the area that remained ignored that is personality traits and leadership style and profile of CEOs in Pakistan and identifies differences on the basis of motivational profile between entrepreneurial and professional CEOs or top managers. The present study will focus to investigate whether entrepreneurs are different from non-entrepreneurs and what differentiate entrepreneurial CEOs from professional CEOs. The majority of the businesses are small medium enterprises; hence it is considered an advantage of the study.

\section{Literature review}

In previous studies entrepreneurial characteristics and attributes persist with continuity. These five psychological dimensions such as need for achievement, locus of control, risk taking propensity, ambiguity tolerance, and Type-A personality (Hornaday and Aboud, 1971). Other view is that all managers fall into three categories of motivational groups (McClelland and Burnham, 1976). The first group is mostly motivated by achievement, the second by affiliation and the third by power. The achievement motive is a non-conscious concern for achieving brilliance in accomplishments through one's individual efforts (McClelland et al, 1961). This achievement motive is one of the most broadly discussed characteristics distinguishing entrepreneurial CEOs from professional CEOs or top managers, as entrepreneurs usually score better on it (McClelland, 1986). Whereas, the professional CEOs or top managers decisions are designed at increasing their popularity rather than promoting the goals of the organization.

In terms of entrepreneurial initiative, the affiliation motive could lead to the decision to create one's business, in order to transfer something or to offer some kind of employment security to its family or children, or legal heirs (Barrow, 1993). Power is another non-conscious concern for acquiring status and having an influence on others. Managers who are generally interested in power recognized that you get things done in organizations, only if you can influence the people around you, so they focus on building power through influence rather than through their individual achievement. The power motive in terms of entrepreneurship motivation could be articulated in the much discussed and established in numerous surveys entrepreneurial characteristics of "locus of control", "autonomy", and "dominance" (Sexton and Bowman, 1985).

McClelland (1965) argued that the following combination of non-conscious motives is the predictive leader effectiveness; high power motivation, moderate achievement motivation, high concern for the moral exercise of power and power motivation greater than affiliation motivation. Managers who are more motivated by power, tied with a high sense of responsibility towards the company are the most effective. They see organizational goals and exhibit more team spirit (McClelland and Burnham, 1976). This finding, however, referred to professional CEOs or top managers and may not be the case of entrepreneurial CEOs. The personality traits approach to entrepreneurs and the problems associated with it have been criticized (Gartner, 1989). However, it is interesting to investigate the existence of different motives among entrepreneurial CEOs and professional CEOs, under the McClelland's traditional theory of non-conscious motivation, as this has formed the basis of the traits-analysis or entrepreneurs (Cromie, 2000; Ratnatunga and Romano, 1997; Alstete, 2002; Hisrich, 2000).

In this study Hornaday and Aboud (1971) model of psychological characteristics motive profile is followed. It is observed that entrepreneurs display moderate risk taking propensities. While subsequent studies have substantiated this tendency in entrepreneurs McClelland (1965). In a similar study it is observed that risk avoidance is stronger among entrepreneurs heading fast growing firms than among those heading slow growth firms (Smith and Miner, 1985). Such situations accord with conceptual models of successful entrepreneurs. A study says that the effective entrepreneur "can correctly interpret the risk situation and then determine policies which will minimize the risks involved (Palmer, 1971). As entrepreneurs scan their environment, therefore, they simultaneously seek to exploit opportunities and to avoid risks (threats), (Welsch and Young, 1982).

Entrepreneurial CEOs have a high need for achievement and are guided by their inner self, motivating their behavior towards accomplishment. Entrepreneurial CEOs is a type of person who needs to do things in his or her own way. Achievement motivation can be defined as "behavior towards competition with a standard of excellence" (McClelland, 1953). Achievement motivation is a trait that is prevalent among entrepreneurs. Research indicates that it is higher in company founders, compared to managers (Begley and Boyd, 1987; Miner, 
Smith, and Bracker, 1989). It is suggested that people with high levels of achievement motivation will be future oriented and will take tasks seriously if they believe that current tasks will influence future goals (McClelland and Koestner, 1992).

Locus of control passes on to the professed control over the events in ones life (Rotter, 1966). People with external locus of control have a tendency that most of the events in their lives outcome from being lucky, being at the right place at the right time, and the behaviors of powerful individuals. In regard to locus of control, a person with an external locus of control believes luck and or powerful others control outcomes relevant to them (Ward, 1993). Studies conducted in the United States, Australia, and Great Britain on locus of control has been found to differentiate entrepreneurs from the general public and middle/seniors managers, as well as to distinguish successful from unsuccessful entrepreneurs (Brockhaus, 1980; Cromie and Johns, 1983; Gilad, 1982).

Risk taking propensity is defined as "the perceived probability of receiving reward linked with the success of situation that is necessary by the individual before he/she will subject himself to the consequences associated with failure, the alternative situation providing less reward as well as severe consequences than the proposed situation" (Brockhaus, 1980). Risk taking is identified as a trait that distinguishes entrepreneurs from non entrepreneurs and managers (Ahmad, 1985' Shane, 1996; Miner et al, 1989).

Individuals recognize ambiguity when they lack ample signal to construct a situation. According to Budner, (1962) ambiguity may originate from uniqueness, complexity, or insolubility. Budner (1962) defines intolerance of ambiguity as the propensity to perceive ambiguous circumstances as threatening; tolerance of ambiguity is the tendency to perceive such conditions as desirable. Given the uncertainty inherent in the entrepreneurial leadership style environment, it is described as the owner's role, i.e., "an ambiguity-bearing role (Schere, 1982). Entrepreneurs may view uncertainty as "an existing stimulus rather than a severe threat". If ambiguity tolerance serves as a motivational channel, it may foster entrepreneurial success. It has been linked with creative behavior and to superior performance in complex tasks (MacDonald, 1970). On the contrary, intolerance to ambiguity has been associated with stereotypic stimuli (Budner, 1985).

Type-A personality is defined as an action-emotion complex that can be observed in any person who is aggressively involved in a chronic, incessant struggle to achieve more and more in less and less time, and if required to do so, against the opposing efforts of other things or other persons (Friedman and Rosenman, 1974). The type-A personality is thus an exaggerated stylistic response to environmental challenge. Major pattern elements include impatience and irritability, time urgency, driving ambition, accelerated activity, and generalized competitiveness. Prior research supports that growth-minded entrepreneurs endeavor to surpass their own results; they compete with themselves more than with others (Timmons, 1985).

Despite modest scores on the competitive dimension, various studies have documented the prevalence of type-A behavior among small business owner/managers. In a recent study, smaller firms respondents had a higher type-A personality means score. Even after external pressures have decreased, the type-A personality behavior pattern remains an enduring characteristics of small business entrepreneurial CEOs (Boyd and Gumpert, 1983). As a result of orientation toward achievement, type-A executives may be more likely to achieve success than their type-B colleagues (Shekelle and Schoenberger and Stamler, 1976). Other studies conducted by various scholars also support this observation (Boyd, Howard, Cunningham, and Rechnitzer, 1977). Actually the entrepreneurial CEOs motivational profile seems to be a subset of entrepreneurial CEOs personality trait and leadership profile. The entrepreneurial CEOs leadership style is different from that of professional CEOs because of motivational profile.

\section{Hypotheses}

H1: The entrepreneurial CEOs will manifest greater scores in need for achievement motive than professional CEOs.

H2: The entrepreneurial CEOs will exhibit higher scores on locus of control motive than professional CEOs.

H3: The entrepreneurial CEOs will score higher on risk taking propensity motive than professional CEOs.

H4: The entrepreneurial CEOs will manifest higher scores on ambiguity tolerance than professional CEOs.

H5: The entrepreneurial CEOs will exhibit greater score on type-A personality than professional CEOs.

\section{Methodology}

\subsection{Sample}

The main objective of the study was to study and explore the motivational profiles of entrepreneurial and professional CEOs. The study used simple random sampling technique and sample was considered to be representative. In this study a total of 190 respondents were contacted and the sample consisted of 124 participants 
(n-124), which contain 62 entrepreneurial CEOs and the equal number of professional CEOs. Data collection is difficult task in Pakistan though but in this case respondents were personally persuaded to get filled in questionnaires and as a result out of the total 190 respondents, 124 responses were received, therefore, the response rate was $65 \%$ as a whole. The study was carried out in the twin cities of Islamabad and Rawalpindi. All selected respondents were considered to be "successful" in their field according to traditional measure of entrepreneurial accomplishment. The entrepreneurial success was defined as the profit growth made by the organization or services delivered by the organization they represent (Bosma et al, 2000).

\subsection{Measuring Instrument}

The need for achievement was measured by five items, from Edwards Personal Preference Schedule (EPPS) developed by (Edwards, 1959), and further validated by Winter (1991). The reliability of the data regarding need for achievement was tested and it was 0.79

The second variable locus of control was measured by using six items, taken from Rotter's scale developed by (Rotter, 1966). Past research has shown Rotter scale to be a reliable and valid scale. In this study the coefficient alpha for locus of control was 0.76

In the study risk taking propensity was measured by using five items, taken from the Jackson Personality Inventory (JPI) scale developed by (Jackson, 1976). Various studies have supported the reliability and validity of the JPI, scale as a measure of generalized risk taking propensity. The data reliability for locus of control was 0.72 .

The ambiguity tolerance was measured by using five items taken from Tolerance-Intolerance of Ambiguity scale developed by (Budner, 1962). The scale measured the willingness of an individual to deal with uncertainty. In the present study the data reliability for ambiguity tolerance was found to be 0.83

The Type-A personality was measured by using five items taken from The Framingham scale of the A/B typology developed by, (Chesney and Rosenman, 1980). The reliability of the data regarding Type-A personality was 0.69 .

Insert Table-1 here

\subsection{Procedure}

The present study theoretical framework is based on leadership effectiveness in general and on entrepreneurial effectiveness in particular (McClelland, 1975, 1985, \& 1986). This is an empirical study conducted in the Pakistani milieu and compared on motivational profiles between entrepreneurial and professional CEOs. In this study the entrepreneurial CEOs considered to be having the designations of Directors, Managing Partners, and Managing Directors, whereas professional CEOs consists of General Managers, Director Generals, and Executive Directors of Public sector organizations. The entrepreneurial CEOs were identified through local chamber of commerce and industry in both cities of Islamabad and Rawalpindi. The professional CEOs were approached through official directory of Government of Pakistan. The present study questionnaire addressed all other aspects concerning characteristics, beliefs, and experiences of the CEOs as well as the establishment, the goals, and motivational profile of the CEOs. In the first stage the Levene's test was applied which revealed that the data qualified for t-Test. Then in the second stage the t-Test was applied to examine the motivational difference between entrepreneurial and professional CEOs. The study analyzed 124 Pakistani entrepreneurial and professional CEOs and compared both on five motives as; need for achievement, locus of control, risk taking propensity, ambiguity tolerance, and type-A personality. In this study rating options were categorized as, $5=$ strongly agree, $4=$ agree, $3=$ neither agree nor disagree, $2=$ disagree, and $1=$ strongly disagree.

\section{Insert Table-2 here}

\section{Results and Findings}

All variables in this study are standardized to a five-point scale, with five as the strongest agreement or highest value and one as the lowest or weakest value. In the present study the Table- 2 shows that mean for need for achievement motive among entrepreneurial CEOs is greater $(4.5032>3.4581)$ than mean for professional CEOs and the value of ' $t$ ' and significant value of $p(p<.0001)$ in Table-3 shows that entrepreneurial CEOs have higher scores on need for achievement and, therefore, they are more influenced by need for achievement.

The Study reveals through Table- 2 that mean for locus of control motive among entrepreneurial CEOs is greater $(4.0430>3.3817)$ than mean for professional CEOs and ' $t$ ' value and significant value of $p(p<.0001)$ in Table-3 confirms that entrepreneurial CEOs have higher scores than professional CEOs on locus of control and, therefore, they are more influenced and motivated to go for unusual goals.

The study demonstrates in Table-2 that mean for risk taking propensity among entrepreneurial CEOs is greater $(4.1935>3.3290)$ than mean for professional CEOs. The study further explains Table- 3 that' $t$ ' value and the 
significant value of $\mathrm{p}(\mathrm{p}<.0001)$ in that entrepreneurial CEOs have higher scores than professional CEOs on risk taking and, therefore, entrepreneurial COEs are more willing to take risk and accept challenges.

The present study explains Table-2 that mean for ambiguity tolerance motive among entrepreneurial CEOs is greater $(4.0258>3.4258)$ than mean for professional CEOs. The study further confirms Table-3 that value of and significant value of $\mathrm{p}(\mathrm{p}<.0001)$ that entrepreneurial CEOs have higher scores than professional COEs on ambiguity tolerance and, therefore, entrepreneurial COEs are more ready to deal uncertain and challenging situations.

The study indicates in Table- 2 that mean for Type-A personality motive among professional CEOs is greater $(4.1677>3.3161)$ than mean for entrepreneurial CEOs and further explains Table-3 that value of $t$ and significant value of $\mathrm{p}(\mathrm{p}<.0001)$ that professional CEOs scores higher than professional CEOs on Type-A personality and, therefore, professional CEOs are more inclined to maintain the status quo.

Insert Table-3 here

\section{Discussions}

In the present study all five variables; need for achievement, locus of control, risk taking propensity, ambiguity tolerance, and type-A personality have been compared with one another for each group of respondents. For the group of professional CEOs type-A personality proved to be the strongest variable. Whereas, entrepreneurial CEOs, the need for achievement is the strongest variable, followed by locus of control, risk taking propensity and ambiguity tolerance, whilst for professional CEOs type-A personality was the foremost motive.

In present study the first hypotheses on the difference of motivational motives need for achievement among entrepreneurial and professional CEOs was confirmed and achievement motive was established to be a discriminating factor among the two groups. Entrepreneurial CEOs scored higher on this motive. The means $(4.5032>3.4581)$ in Table-2 shows that need for achievement is higher in entrepreneurial CEOs and value of " $\mathrm{t}$ " and significant value of $\mathrm{p}(\mathrm{p}<.0001)$ in Table-3 shows that entrepreneurial CEOs scored higher on need for achievement as compared to professional CEOs. This finding is in harmony with prior research stating need for achievement as primary characteristics of entrepreneurial CEOs (McClelland, 1986; Hisrich et al., 1996; Orham and Scott, 2001).

In present study the motive need for achievement has been confirmed and achievement motive is being established to be a discriminating factor among entrepreneurial CEOs. This finding is in harmony with prior research stating need for achievement as primary characteristics of entrepreneurs (McClelland, 1986; Hisrich et al., 1996; Orham and Scott, 2001). According to McClelland (1990) need for achievement has shown significant relation to entrepreneurship across several previous studies (Johnson, 1990, and Venkatapathy, 1984). McClelland (1958, 1961, 1987, and 1990) has shown the importance of the need for achievement motive for economic development (Kock, 1965; McClelland, 1965; Wainer and Rubin, 1969; Morris and Fargher, 1974; Durand and Shea, 1974). This finding is in line as observed by Bird (1989) and Sexton \& Bowman-Upton $(1989,1984)$ that a high need for achievement is associated with the entrepreneurial model. This study finding is that entrepreneurial CEOs have higher need for achievement than professional CEOs.

In the present study the second hypotheses on the difference of motivation motives locus of control among entrepreneurial and professional CEOs was confirmed and locus of control was established to be a distinguishing factor among the two groups. The means $(4.0430>3.3817)$ in Table- 2 shows that entrepreneurial CEOs scored higher on locus of control. The present study further explains that value of " $t$ " and significant value of $p(p<.0001)$ in Table-3 shows that entrepreneurial CEOs scored higher on locus of control motive as compared to professional CEOs. This finding is in line with the previous research studies stating locus of control as primary characteristics of entrepreneurial CEOs (Boone, Brabander, and Witteloose tuijn, 1996; Begley and Boyd, 1986; Ward. 1993).

Locus of control has been found, in studies conducted in the United States, the United Kingdom, and Australia; differentiate entrepreneurs from the middle/top managers, and general public, as well as to discriminate successful from unsuccessful entrepreneurs (Brockhaus, 1980; Cromie and Johns, 1983; Gilad, 1982). Pertaining to this study, another research says that internals are more like to display entrepreneurial qualities (Wheatley, Anthony, and Maddox, 1991). Smith and Miner (1983) unearth entrepreneurs different from that of top managers in terms of managerial motivation. Other research arrived at the same conclusions (Hull, Bosley, and Udell, 1980; Timmons, Smollen, and Dingee, 1985). Another study states that entrepreneurial behavior (locus of control as measured by the personality attributes) is supposed to be a key success factor (Ibrahim and Goodwin, 1986).

In present study the third hypotheses on the difference of motivational motives, i.e. risk taking propensity among entrepreneurial and professional CEOs was confirmed and risk taking propensity was established to be a 
distinguishing factor among the two groups. In this study entrepreneurial CEOs scored higher on risk taking propensity. The means $(4.1935>3.3290)$ in Table-2 shows that entrepreneurial CEOs scored higher than professional CEOs. The study further clarifies value of " $\mathrm{t}$ " and significant value of $p(p<.0001)$ in Table-3 shows that entrepreneurial CEOs scored higher on risk taking propensity as compared to professional CEOs. This finding is in sequence with the previous studies stating that risk taking propensity as primary attribute of entrepreneurial CEOs (Cromie, Callaghan, and Jensen, 1992; Brockhaus, 1980; Mancuso, 1975) In another study it is stated that likely entrepreneurs have greater needs for autonomy, creative tendencies, and higher risk taking propensity than those of managers (Cromie, Callaghan, and Jensen, 1992). Mancuso's (1975) expressed that entrepreneurs' desire a moderate level of risk. Thus earlier studies have concerned with the entrepreneurs risk taking propensity may have correctly found the majority of entrepreneurs to have a tendency towards moderate levels of risk, but they may have failed to recognize that the same characteristics is also true for the general population (Brockhaus, 1980). Another study reveals that entrepreneurial CEOs have a tendency for planning risk taking (Miller and Toulouse, 1986).

In this study the fourth hypotheses on the difference of motivational motives, i.e. ambiguity tolerance among entrepreneurial and professional CEOs was confirmed and ambiguity tolerance was established to be a distinguishing factor between the two types of CEOs. In the present study the means $(4.0258>3.4258)$ in Table-2 shows that entrepreneurial CEOs scored higher value of " $t$ " and significant vale of $p(p<.0001)$ in Table-3 that entrepreneurial CEOs scored higher ambiguity tolerance as compared to professional CEOs. This finding is in succession with the preceding studies describing that ambiguity tolerance as primary trait of entrepreneurial CEOs (Bernardo and Welch, 2001; Ellsberg, 1961; Begley and Boyd, 1986).

Ambiguity tolerance can be a powerful creative motivation. It supports entrepreneurs to think differently. Ambiguity tolerance, however, forces entrepreneurial CEOs to stretch their minds and hearts beyond their normal boundaries and to discover creative opportunities they might otherwise pay no attention to this. This is not a cup of every body's choice because it requires too much. This stressful job entails to face so many pressures and pain in daily life. It's a demanding job and every body can not perform this painful duty. Entrepreneurs are famous for asking questions and then going beyond the first answer to explore and investigate other possible options. The result is that they often find business opportunities by creating ambiguous situations. This entrepreneurial trait makes them different from others, including professional CEOs and top managers (Regotti and Ryan, 1997; Gervais et al, 2000).

In the present study the fifth hypotheses on the difference of motivational motives, i.e. type-A personality among entrepreneurial and professional CEOs was rejected and type-A personality motive was predicted to be a distinctive feature among the two groups. In this study professional CEOs scored higher on type-A personality motive as compared with entrepreneurial CEOs. The means $(4.1677>3.3161)$ in Table-2 shows that professional CEOs scored higher. The study further reveals the value of " $t$ " and the significant value of $p(p<.0001)$ in Table-3 shows that professional CEOs scored higher on type-A personality as compared to entrepreneurial CEOs. This finding is in order with the prior studies unfolding that type-A personality as crucial attribute of professional CEOs (Begley and Boyd, 1986; Kuratko and Hodgetts, 1998; Akande, 1992; Butter, 1992; Butter, 1996; Mathew and Haynes, 1986).

\section{Conclusions}

After analyzing the data the study reached to the conclusion the first hypothesis that entrepreneurial CEOs will score higher on need for achievement motive was approved in the light of higher mean and significant value of $\mathrm{t}$. The results proved that entrepreneurial CEOs scored higher on need for achievement. Entrepreneurial CEOs higher means shows that they are more likely to be motivated by need for achievement (see table 2). Therefore, the study can claim that there is a significant difference between entrepreneurial CEOs and professional CEOs (see table 3). Consequently, the study can predict that entrepreneurial CEOs are more motivated by need for achievement motive because of their personality traits and leadership style as compare to professional CEOs.

The second hypothesis that entrepreneurial CEOs will score higher on locus of control motive was proved in the light of higher mean and significant value of t. The results proved that entrepreneurial CEOs scored higher on locus of control. Entrepreneurial CEOs higher means shows that they are more likely to be motivated by locus of control (see table 2). Therefore, the study can say that there is a significant difference between entrepreneurial CEOs and professional CEOs (see table 3). Hence, the study can predict that entrepreneurial CEOs get more motivated by higher locus of control due to personality traits and leadership profile as compare to professional CEOs.

The third hypothesis that entrepreneurial CEOs will score higher on risk taking propensity motive was confirmed by higher mean and significant value of t. The result shows that entrepreneurial CEOs scored higher on risk taking 
propensity. Entrepreneurial CEOs higher means shows that they are more likely to deal with risk taking propensity (see table 2). Therefore, the study can say that there is a significant difference between entrepreneurial CEOs and professional CEOs on risk taking propensity (see table 3). Thus, the study can predict that entrepreneurial CEOs take more risk and challenges because of personality traits and leadership style as compared with their counterparts, professional CEOs.

The fourth hypothesis that entrepreneurial CEOs will score higher on ambiguity tolerance motive was also confirmed because of higher mean and significant value of t. The result shows that entrepreneurial CEOs scored higher on ambiguity tolerance. Entrepreneurial CEOs higher means shows that they have more ambiguity tolerance (see table 2). Therefore, in the light of results the research can predict that there is a significant difference between entrepreneurial CEOs and professional CEOs on ambiguity tolerance (see table 3). Therefore, the study can foresee that entrepreneurial CEOs will take more stress, and pressure due to personality traits and leadership style as compare to professional CEOs.

The last and fifth hypothesis that entrepreneurial CEOs will score higher on type-A personality was rejected due to higher mean and significant value of $t$. The result shows that entrepreneurial CEOs scored lower on type-A personality, rather professional CEOs scored higher on type-A personality. Professional CEOs higher mean shows that they are type-A personality (see table 2). Therefore, in the light of results it is said that there is a significant difference between entrepreneurial CEOs and professional CEOs. Hence, it is forecasted that professional CEOs will score higher on type-A personality because of personality and leadership style as compare to entrepreneurial CEOs. In the light of this study finding it is predicted that entrepreneurial CEOs personality traits and motivational profile are different. The entrepreneurial CEOs personality traits and motivational profile stress on need of achievement, locus of control, risk taking propensity, and ambiguity tolerance and most of the entrepreneurs and entrepreneurial CEOs follow this motivational profile.

\section{Implications}

This study is going to be invaluable in SME dominated economy like Pakistan, where finding of this research can be used for the development and encouragement among younger generations to opt entrepreneurship. One of the key implications of this study is deriving some lessons from the identified characteristics of entrepreneurial and professional CEOs for the preparation and training of young leaders for both large and small organizations. The future policy making agencies can learn lessons to make meaningful plans and policies to prepare future generations for the future challenges of entrepreneurship. Policy makers can promote entrepreneurship through SMEs to strengthen future economy of the nation. This would help to increase the awareness of both educationists and students to follow entrepreneurial careers in the times to come. This study will help to understand entrepreneurial personality traits and motivational profile to carve and trained future entrepreneurs. The pedagogy institutions can train and carve leadership style and motivational profile amongst future entrepreneurs.

\section{Limitations}

Like all research studies, this study is not without some prominent limitations. First, in the present study only five variables motivational were studied. Future studies should seek to study more variables to demonstrate motivational impact. Second, limitation is the geographic sample limited to Islamabad/Rawalpindi areas. Understanding the empirical versatility of the phenomenon requires further investigation. The intercity and inter organizational sample would increase our knowledge of the potential differences in motivational motives. Third, limitation of the present study was that it considers entrepreneurial CEOs and professional CEOs in the public sector. The future studies should seek to investigate the entrepreneurial CEOs and private professional CEOs. The future studies will enable to understand the motivational differences among the CEOs. Fourth, the present study was conducted in the Pakistani milieu. The future studies should investigate motivational motives in the different working environment so that entrepreneurial CEOs and professional CEOs can enhance their knowledge and apply according to their local environment.

\section{References}

Afzalur Rahim. (1996). Stress, Strain, and Their Moderators: An Empirical Comparison of Entrepreneurs and Managers. Journal of Small Business Management, 34: 46-58

Ahmad, S.U. (1985). nAch, Risk Taking Propensity, Locus of Control and Entrepreneurship. Personality and Individual Differences, Vol. 6 (6): 781-2

Akande, A. (1992). Coping with Entrepreneurial Stress. Leadership and Organization Development Journal, Vol. 13 (2): 27-32

Alstete, J.W. (2002). On becoming an entrepreneur: an evolving typology. International Journal of 
Entrepreneurial Behavior and Research, Vol. 8: 222-234

Barrow, C. (1993). The Essence of Small Business, Prentice-Hall, Hemel Hempstead

Begley T.M and Boyd, D.P. (1987). Psychological Characteristics Associated with Performance in Entrepreneurial Firms and Smaller Businesses. Journal of Business Venturing, Vol. 2: 79-93.

Begley, T.M., and Boyd, D. P. (1986). Psychological Characteristics Associated with Entrepreneurial Performance Frontiers of Entrepreneurship Research. Babson Center for Entrepreneurial Studies, Wellesley, Mass.

Borland, C. (1974). Locus of Control, Need for Achievement and Entrepreneurship (Doctoral dissertation. The University of Texas at Austin,

Bosam, N., van Praag, M., and de Wit, G. (2000). Determinants of successful entrepreneurship, Research Report 0002/E, SCALES, (Scientific Analysis of Entrepreneurship and SMEs).

Boyd, D. P., and Gumpert, D.E. (1983). The Effects of Streets on Early-Stage Entrepreneurs in Hornaday, Timmons, and Vesper (eds.)

Boyd, D.P., Howard, J.H., Cunningham, D.A., and Rechnitzer, P.A. (1977). Work Patterns Associated with Type A Behavior: A Managerial Population. Human Relations, Vol. 30: 825 - 836.

Brockhaus, R. H. (1975). I-E Locus of Control Scores as Predictors of Entrepreneurial Intentions. Proceedings, Academy of Management, New Orleans,

Brockhaus, R. H. (1980a). Risk taking propensity of entrepreneurs. Academy of Management Journal, Vol. 23: $509-20$

Budner, S. (1962). Intolerance of Ambiguity as a Personality Variable. Journal of Personality, vol. 30: 29-50

Butter, E.H. (1992). Entrepreneurial Stress: Is it Hazardous to Your Health. Journal of Management, Issues 4: 223-240

Cantilon, R. (1931). Uncertainty bearing role of the entrepreneur. H. Higgs, Macmillan, London.

Chesney, M.A., and Rosenman, R. H. (1980). Type A Behavior in the Work Setting in Copper, C., Payne, R. (Eds), Current Concerns in Occupational Stress, Wiley, London.

Cromie, S. (2000). Assessing Entrepreneurial Inclination. European Journal of Work and Organizational Psychology, Vol. 9 (1): 7-30

Cromie, S., and Johns, S. (1983). Irish Entrepreneurs: Some Personal Characteristics. Journal of Occupational Behavior 4: 317-324

Cromie, S., Callaghan, I., and Jensen, M. (1992). Entrepreneurial Tendencies of Managers: a research note. British Journal of Management, Vol. 3 (1): 1-5

Edwards, A.L. (1959). Edwards Personal Preferences Schedule. The Psychological Corporation, New York.

Ellsberg, D. (1961). Risk, Ambiguity and the Savage Axiom. The Quarterly Journal of Economics, Vol. 75: 643-669

Friedman, M., and Rosenman, R. H. (1974). Type A Behavior and Your Heart, Fawcett, Greenwich, Conn.

Gartner, W. (1989). Who is an Entrepreneur?, Is the Wrong Question. Entrepreneurship theory and Practice, Vol. 13(4): 47-68

Gervais, S., Heaton, J., and Odean, T. (2000). Capital Budgeting in the Presence of Managerial Overconfidence and Optimism. Mimeo, University of Pennsylvania.

Gilad, B. (1982). On Encouraging Entrepreneurship: An Interdisciplinary Analysis. Journal of Behavioral Economics, 11 (Summer):132-163

Hisrich, R. D., \& Brush, C. G. (1985). The Women Entrepreneur: Characteristics and Prescriptions for Success. Lexington Books, Lexington,, MA

Hisrich, R.D. (2000). Can psychological approaches be used effectively? An overview. European Journal of Work and Organizational Psychology, Vol. 9 (1):93-96

Hornaday, J. A., and Aboud, J. (1971). Characteristics of Successful Entrepreneurs. Personal Psychology, Vol. 24:141-153

Hull, D.L., Bosley, J.J., and Udell, G. G. (1980). Reviewing the Hunt for the Heffalump: Identifying Potential 
Entrepreneurs by Personality Characteristics. Journal of Small business Management, Vol. 18(1):11-18

Ibrahim, A,B., and Goodwin, J.R. (1986). Perceived Causes of Success in Small Business. American Journal of Small Business, 11(2): 41-50

Jackson, D.N. (1976). Jackson Personality Inventory. Research Psychologists Press. Goshen, N. Y. New York.

Kautonen ,T, Tornikoski, E.T., and Kibler, E. (2009). Entrepreneurial intentions in the third age: The Impact of Perceived age Norms. Small Business Economics.

Kirzner, LM. (1981). Uncertainty, discovery, and human action. paper presented at the New York University Liberty Fund Centenary Conference on Ludwig von Mises, New York, NY

Knight, F. H. (1921). Risk, Uncertainty, and Profit. Houghton Mifflin, New York, NY

Kounin, J. (1948). The Meaning of Rigidity: A Reply to Heinz Werner. Psychological Review, Vol. 55:157-166

Kuratko, D.F., and Hodgetts, R. M. (1998). Entrepreneurship: A Contemporary Approach. The Dryden Press, Harcourt Brace College Publishers

MacDonald, A.F. (1970). Revised scale for Ambiguity Tolerance: Reliability and Validity. Psychological Reports, 26:791-798

Mancuso, J.R. (1975). The Entrepreneurship 'Quiz' in C.M Baumback, and Mancuso, J.R (Eds), Entrepreneurship and Venture Management'. Englewood, N.J.: Prentice-Hall, Inc.

Mathews, K.A and Haynes, S. C. (1986). Type A Behavior Pattern and Coronary Disease Risk. American Journal of Epistemology, Vol. 123:923-960

McCleland, D.C., \& Koestner, R. (1992). The Achievement Motive. In Charles P. Smith (eds). Motivation and Personality': Hand Book of Thematic Content Analysis: Cambridge University Press. New York, NY

McClelland, D. C. (1961). The Achieving Society. Van Nostrand Rinehold, Princeton, NJ

McClelland, D. C. (1965). N Achievement and Entrepreneurship. Journal of Personality and Social Psychology, Vol. 1: 389-392.

McClelland, D. C. (1986). Characteristics of successful entrepreneurs, Keys to the Future of American Business, Proceeding of the $3{ }^{\text {rd }}$ Creativity, Innovation and Entrepreneurship Symposium, US Small Business Administration and the National Center for Research in Vocational Education, Framingham, MA

McClelland, D.C. (1953). The Achievement Motive. Appleton-Century-Crofts. S. New York, N.Y

McClelland, D.C., and Burnham, D.H. (1976). Power is the great motivation. Harvard Business Review, Vol. 54 (2): 100-110

Meyer, H. H., Walker, W. B., \& Litwin, G. H. (1961). Motive Patterns and Risk Preferences Associated with Entrepreneurship. Journal of Abnormal and Social Psychology, Vol. 63(4):570-574

Miller, D., and Toulouse, J. (1986). Chief Executive Personality and Corporate Strategy and Structure in Small Firms. Management Science, Vol. 32: 1389-1409

Miner, J.B., Smith, N.R., \& Bracker, J.S. (1989), Role of Entrepreneurial Task Motivation in the Growth of Technologically Innovative Firms. Journal of Applied Psychology, Vol. 2:554-560

Nunnally, J. C. (1979). Psychometric Theory. New York: McGraw-Hill

Orham, M., and Scott, D. (2001). Why women enter into entrepreneurship: an explanatory model. Women in Management Review, Vol. 16:232-243

Palmer, M. (1971). The Application of Psychological Testing to Entrepreneurial Potential. California Management Review, Vol. 13(3):32-38

Ratnatunga, J., and Romano, C. (1997). A citation Classics' analysis of articles in contemporary small enterprise research. Journal of Business Venturing, Vol. 12(3):197-212

Regotti, L., and Ryan, M. (1997). Knightian Uncertainty, Entrepreneurship and Corporate Culture. Mimeo University of Auckland

Rotter, J. B. (1966). Generalized Expectancies for Internal Versus External Control of Reinforcement. Psychological Monographs: General and Applied, 80(1):1-28

Say, J. B. (1845). A Treatise on Political Economy. Grigg \& Elliot, Philadelphia, PA 
Schere, J. L. (1982). Tolerance of Ambiguity as a Discriminating Variable Between Entrepreneurs and Managers. Proceedings of the National Academy of Management. 404-408

Schrage, H. (1965). The R \& D Entrepreneur: Profile of Success. Harvard Business Review, Vol. 54( 4): 56-59

Schumpeter, J. A. (1934). The Theory of Economic Development. Harvard University Press, Cambridge, MA

Sexton, D.L, and Bowman, N. (1984). Personality Inventory for Potential Entrepreneurs and Small Business Owners in New Venture Formation, “ in J. A. Hornaday, F. Tarpley, J. A. Timmons and K. H. Vesper (Eds), Frontiers of Entrepreneurship Research, Babson Center for Entrepreneurial Studies, Wellesley, Mass.

Sexton, D.L., and Bowman, N. (1985). The entrepreneur: a capable executive and more. Journal of Business Venturing, Vol. 1(1):129-140

Shane, S. (1996). Explaining Variation in Rates of Entrepreneurship in the United States: 1899-1988. Journal of Management, Vol. 22: 747-781

Shapero, A. (1975). The Displaced, Uncomfortable Entrepreneur. Psychology Today, Vol. 9(6):83-88

Shekelle, R.B., Schoenberger, J.A., and Stamler, J. (1976). Correlates of the JAS type A Behavior Pattern Score. Journal of Chronic Diseases, 29:381-394

Smith, N. E., and J. B. Miner. (1983). Type of Entrepreneurs, Type of Firm, and Managerial Motivation: Implications for Organizational Life Cycle Theory. Strategic Management Journal, Vol. 4:325-340

Thompson, E. R. (2009). Individual entrepreneurial intent: construct clarification and development of an internationally reliable metric. Entrepreneurship: Theory and Practice, 33:669-604

Timmons, J. A. (1985). New Venture Creation, $2^{\text {nd }}$ ed. Richard D. Irwin, Homewood

Timmons, J.A., Smollen, L.E., and Dingee, A.L.M. (1985). New Venture Creation: A Guide to Entrepreneurship. Hamate, III.: Irwin.

Ward, E.A. (1993). Motivation of Expansion Plans of Entrepreneurial and Small Business Managers. Journal of Small Business Management, Vol. 31(1):32-39

Welsch, H. P., and Young, E. C. (1982). The Information Source Selection Decision: The Role of Entrepreneurial Personality Characteristics. Journal of Small Business Management, Vol. 20:49-57

Wheatley, W. J., Anthony, W. P., and Maddox, E. N. (1991). Selecting and Training Strategic Partners with Imagination and Creativity. Journal of Creative Behavior, Vol. 25:52-60.

Winter, D. G. (1991). Measuring Personality at a Distance: Development of an Integrated System for Scoring Motives in Running Text, in Stewart, A.J., Healy, J.M., and Ozer, D.J. (Eds.), Perspectives in Personality, part B: Approaches to understanding Lives, Jessica Kingsley, Publishers, London.

Table 1. Reliability of data

\begin{tabular}{|l|c|c|}
\hline Variable & N & Cronbach alpha \\
\hline Need for Achievement & 124 & 0.79 \\
\hline Locus of Control & 124 & 0.76 \\
\hline Risk Taking Propensity & 124 & 0.72 \\
\hline Ambiguity Tolerance & 124 & 0.83 \\
\hline Type A Personality & 124 & 0.69 \\
\hline
\end{tabular}

According to Nunnally (1979), operationally, reliability is adequate in the early stages of developing a measure if .70 or higher is attained. 
Table 2. Group Statistics; CEOs, Means, and Standard Deviations ( $1=$ strongly disagree and $5=$ strongly agreed, hence we can say 1 is lowest and 5 is highest).

\begin{tabular}{|l|l|l|l|c|}
\hline Variable & CEOs & $\mathrm{N}$ & Mean & Std. Deviation \\
\hline Need for Achievement & Entrepreneurial & 62 & 4.5032 & .24696 \\
& Professional & 62 & 3.4581 & .20780 \\
\hline Locus of Control & Entrepreneurial & 62 & 4.0430 & .58209 \\
& & & & \\
& Professional & 62 & 3.3817 & .43289 \\
\hline Risk Taking Propensity & Entrepreneurial & 62 & 4.1935 & .30324 \\
& & & & .36350 \\
\hline Ambiguity Tolerance & Enofessional & 62 & 3.3290 & .19143 \\
& Propreneurial & 62 & 4.0258 & .35681 \\
\hline Type A Personality & Entrepreneurial & 62 & 3.3161 & .42825 \\
& & & & .35061 \\
\hline
\end{tabular}

Std. stands for standard

CEO stands for Chief Executive Officer

Table 3. Analysis: Independent Sample Test

\begin{tabular}{|l|l|c|c|c|}
\hline \multicolumn{1}{|c|}{ Variable } & \multicolumn{1}{|c|}{ CEOs } & $\mathrm{N}$ & $\mathrm{t}$ & Sig. (2tailed) \\
\hline Need for Achievement & Entrepreneurial & 62 & 18.030 & .000 \\
& Professional & 62 & 18.030 & .000 \\
\hline Locus of control & Entrepreneurial & 62 & 5.076 & .000 \\
& Professional & 62 & 5.076 & .000 \\
\hline Risk Taking Propensity & Entrepreneurial & 62 & 10.168 & .000 \\
& Professional & 62 & 10.168 & .000 \\
\hline Ambiguity Tolerance & Entrepreneurial & 62 & 8.250 & .000 \\
& Professional & 62 & 8.250 & .000 \\
\hline Type A Personality & Entrepreneurial & 62 & -8.567 & .000 \\
& & & & .000 \\
\hline
\end{tabular}

$\mathrm{P}$ value $(\mathrm{p}<.0001)$ 